\title{
Theoretical considerations of the plant association
}

\author{
J. LOOMAN
}

Canada Department of Agriculture, Experimental Farm, Swift Current, Saskatchewan

\section{Summary}

The controversies about the classification of plant communities arise mainly from the lack of a clear definition of the plant association. According to the Theory of Tolerance the distribution of plant species is controlled primarily by climate, and secondarily by edaphic factors. Hence, the distribution of a species within a climatic region is according to its tolerance to edaphic conditions. Species with similar tolerances therefore form a species pool from which the vegetation on sites of given edaphic conditions must be selected. Because species have different ranges of tolerance these species pools contain species of wide tolerance as well as species truly indicative of the habitat-type.

Considering the species pool the equivalent of an alliance or association sensu Braun-Blanquet, the indicator species are the kensorts of the association or alliance. Hence, the association is an ecological unit, characterized by its floristic composition. In addition, the association is a stage in successional development, and is often composed of life-forms specially adapted to the ecology and successional status of the association. This leads to the following definition: The plant association is an aggregate of plant species forming an ecological unit with a definite successional status and of uniform physiognomy, recognizable by its floristic composition.

It is proposed to use ecology, successional status and, under certain circumstances, life-form spectra as additional criteria in the classificatory system of the Zürich-Montpellier school to make the system universally valid.

\section{Introduction}

Classification of plant communities is a controversial subject. WHITTAKER (1962) expressed this adequately in the opening sentence of his paper:

No aspect of synecological science has been the subject of more discussion and argument, or has had a more crucial role in the evolution of ecological schools, than the classification of natural communities.

Nevertheless, classification is necessary; some of its opponents admit this (GLEAson, 1939), and present a classification of plant communities for the sake of convenience, and to distinguish between and describe the salient features of plant communities (CurTIS, 1959). It is easier for Curtis to speak of "Dry Prairie" or "Cedar Glade" than to attempt an elucidating description each time the concept of these plant communities must be conveyed: once description and concept have been accepted and are known, the name of the concept suffices.

The controversies are not so much aboct this basic type of classification as about the finer distinctions between types of Dry Prairie and types of Cedar Glades, and the methods used to distinguish between and describe these types. The controversies

Received for publication 21st December, 1964. 
thus revolve around Gleason's fundamental question: "What is a plant association?" (1939).

This paper is intended to consider this question in the light of available data, and to develop a theory on the nature of the plant association which makes it possible to classify plant associations in a logical system.

\section{Nature of the plant association}

\subsection{The theory of tolerance}

The considerations are based mainly on Goon's theory of tolerance (1953) which states that plant distribution is controlled primarily by climatic factors and secondarily by edaphic factors.

The theory is based on some well-known facts of plant distribution. The geographic distribution of many species, genera and even families can be given in terms with

climatic connotations: tropical, temperature, arctic, or with finer distinctions. CLEMENTS (1905) proposed to determine the boundaries of "floristic provinces" by the distribution limits of the principal species, and checked by the limits of species typical for each province. That it is possible to determine "climatic boundaries" by this or similar methods has been shown by WEAvER and BRUNER (1954), CURTIS (1959) and LOOMAN (1962, 1964). Several genera have well-known edaphic connotations: Salicornia and Suaeda are virtually synonymous with "Salt Marsh"; Sphagnum with "Acid Peat bog"; Ammophila and Calamovilfa with "Sand Dunes".

The theory of tolerance means more than these correlations between the distribution of plant species and climatic or edaphic factors. It also means that, within a floristic province or climatic region, the climate ceases to be the primary controlling factor of plant distribution, and that this role is taken over by edaphic factors. In other words, within a climatic region the flora of that region is distributed according to edaphic conditions, or, in terms which include topography and microclimate, according to "habitat-types". Thus, the species complement of the habitat-type "Salt Marsh" in climatic region $\mathbf{A}$ may differ from that on the same habitat-type in climatic region $\mathbf{B}$. In both regions the species complements of the salt marsh and peat bog are different.

The following premises may be formulated from the theory of tolerance: -

1. Stands on a given habitat-type but in different climatic regions differ in floristic composition.

2. Stands on different habitat-types in a given climatic region differ in floristic composition.

3. The flora of a climatic region is composed of "species pools", each adapted to a given habitat-type.

4. The species in stands on sites of a given habitat-type must be selected from the species pool for that habitat-type under the climate of the region in which the stands are located:

\subsection{Concept of the plant association}

The 6th International Botanical Congress (1935) recommended that the term "plant association" be used exclusively in the sense of Zürich-Montpellier. The plant association in this sense is a unit composed of stands in which a "characteristic combination" (kengroup) of species occurs. The kengroup consists of species (kensorts) not present, or at least much less abundant, in other associations. Although based on floristics 
only the association is considered a sensitive indicator of the habitat (BRAUN-BLANQUET, 1951). The kengroup thus identifies the association as well as the habitat, and kensorts are indicators of the habitat. Consequently, the plant association in the sense of Zürich-Montpellier is the species pool, or part of the species pool, for a given habitat-type within a climatic region.

There remains, however, an important difference between the concepts of the plant association and the species pool. In the plant association the kensorts are "faithful" to the (floristic) association; in the species pool concept the kensorts are associated with the habitat-type, and their fidelity is ecological rather than floristic. BRAUNBLANQUET's discussion of the causes of fidelity (1951) is essentially a discussion of the ecological-tolerance and adaptation of the kensorts: the presence of species $A$, $B, C \ldots$ indicates an environment in which species $X, Y$ and $Z$ can occur, but if the same environment can also be indicated by species $1,2,3 \ldots, X, Y$ and $Z$ can occur in that environment also.

This ecological explanation of the concepts "kensort" and "fidelity" is more or less obscured by the emphasis on floristics, which relates these concepts to a grouping of species rather than to a habitat-type. Yet, the ecological tolerance of species makes them kensorts of more or less fidelity, and shows that the existence of recognizable and describable groupings of species is not accidental as maintained by adherents of vegetational continuity (GLEASON, 1939; CuRTIS, 1959).

The species in a species pool can be divided into four broad categories of ecological tolerance to climatic and edaphic conditions: -

$\begin{array}{rll} & \text { Climate } & \text { Habitat } \\ \text { I } & \text { wide } & \text { wide } \\ \text { II } & \text { narrow } & \text { wide } \\ \text { III } & \text { wide } & \text { narrow } \\ \text { IV } & \text { narrow } & \text { narrow }\end{array}$

Species of categories III and IV form the kengroup of the species pool: they are indicators of the habitat-type. Species of categories II and IV are indicators of the regional climate. Obviously, species in category IV are of higher fidelity to any floristic grouping in the region than those of category III which can also occur in floristic groupings in other climatic regions. Yet, any two species in these categories may have an equally narrow tolerance for the habitat-type, and thus be equally faithful in the ecological sense.

The habitat-type is not necessarily uniform. It may, for example, consist of sites on "dry, eroded, highly calcareous soils", and include all soil textures, degrees of stoniness, and different slopes. However, the species in any stand on a site of this habitattype must be selected from a species pool composed of species whose ecological tolerance coincides with the conditions prevalent in the habitat-type. The number of narrow tolerance species in a pool is limited; hence, the similarity in species composition of any two stands depends largely on the similarity of environmental conditions prevailing in the sites on which the stands occur. A species pool may thus represent a single association, or several associations with similar ecological characteristics (alliance).

Fidelity thus has several levels; some species are faithful to the more generalized habitat-type of the alliance, others have a less wide tolerance and occur only in specialized environments within the habitat-type. In either case the abundance of the 
species is a good measure of the degree of their fidelity. DAMMAN and DE VRIEs (1954) have shown that the frequency percentages of association kensorts increase with increasing frequency of a combination of two or more species which are alliance or even order kensorts. The same phenomenon has been noted in Saskatchewan. In the alliance Eriogonion flavi (LoOMAN, 1963) on dry, eroded, calcareous soils, for example, the abundance of rather rare species increases with the abundance of alliance kensorts. In addition, the number of kensorts per stand and the presence percentages of the kensorts increase, while "accompanying" species of categories I and II decrease in every respect. In other words, the more abundant the kengroup species, the purer the stands.

\subsection{Succession and continuity}

If the foregoing is true and fidelity indicates the width of the ecological tolerance of a species, rather than its binding to a floristic group, the relationship between species in an association is indirect, i.e. through the environment. Although the presence of other kensorts may enhance or hinder the performance of a given kensort, this presence is not an a priori requirement. The environmental conditions required by a species may be filled directly by the environment, or if other species are needed to create a certain "niche", by any species capable of creating this niche, or even by artificial manipulation of the environment. Because in a climatic region the species pool for a given habitat-type is small, the number of possible combinations of kensorts for any one site is limited. Moreover, combinations of alliance kensorts are more likely to occur frequently, and some association kensorts may "never" occur alone.

The degree to which pairs of species are faithful to the same habitat-type can be expressed as "correlation of occurrence" (DE VRIES et al., 1954). Calculation of the correlation coefficient is from a twofold table: -

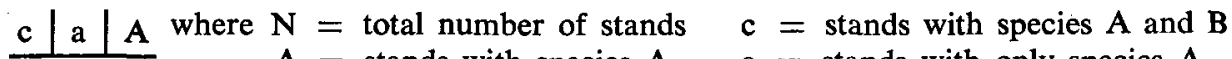

$$
\begin{aligned}
& A=\text { stands with species } A \quad a=\text { stands with only species } A \\
& P=\text { stands without species } A \quad b=\text { stands with only species } B \\
& \text { B }=\text { stands with species } B \quad d=\text { stands with neither } A \text { nor } B \\
& \mathbf{Q}=\text { stands without species } \mathbf{B}
\end{aligned}
$$

The rank-correlation coefficient $T$ is calculated with

$$
\frac{\mathrm{c} \times \mathrm{d}-\mathrm{a} \times \mathrm{b}}{\sqrt{\mathrm{A} \times \mathrm{P} \times \mathrm{B} \times \mathrm{Q}}} \text {, and } \mathrm{r}=\sin \left(\mathrm{T} \times 90^{\circ}\right) \text {. }
$$

The coefficient $\mathrm{r}$ can be used to construct two- or three-dimensional vegetation models (DE VRIES et al., 1954; LOOMAN, 1963), in which clusters of species represent associations or alliances. Although the position of a species in the model is in relation to several other species, and does not represent a median of its ecological tolerance, each cluster also represents a habitat-type.

Three-dimensional models show more than the relative positions of species, vegetation units and habitat-type. The general shape of the model constructed for the grasslands of Saskatchewan (LoOMAN, 1963) led to the inference that a complete model, incorporating all species, would be a spheroid. Pioneer grassland communities would be located at the periphery of the model, more advanced communities towards the center, and the "climax" at the center. One hemisphere of the model would represent "dry" communities, the other hemisphere "wet" communities. Consequently, a theoret- 
ical successional sere, progressing from pioneer vegetation to the forest climax, would move from a point on the periphery of the model towards the center. Later addition of species to the model fully confirmed this idea.

According to the premise that stands on a given habitat-type but located in different climatic regions differ in floristic composition, the correlation of occurrence between kensorts of two related associations in different climatic regions must be negative, because these species do not occur together. At the same time, however, alliance kensorts with wide climatic tolerance may occur in both associations. Consequently, two species negatively correlated with each other can have positive correlations with a third species. In a vegetation model incorporating species from different climatic regions this must result in "multiple representation" of plant communities and habitattypes at all levels of successional development. The FIGURE presents a schematic vegetation model based on the position of associations in a three-dimensional vegetation model of the Northern Great Plains in Canada. A, B, and C are habitat-types; 1,2 and 3 are climatic regions; $\mathrm{I}-\mathrm{V}$ are stages in successional development. Though

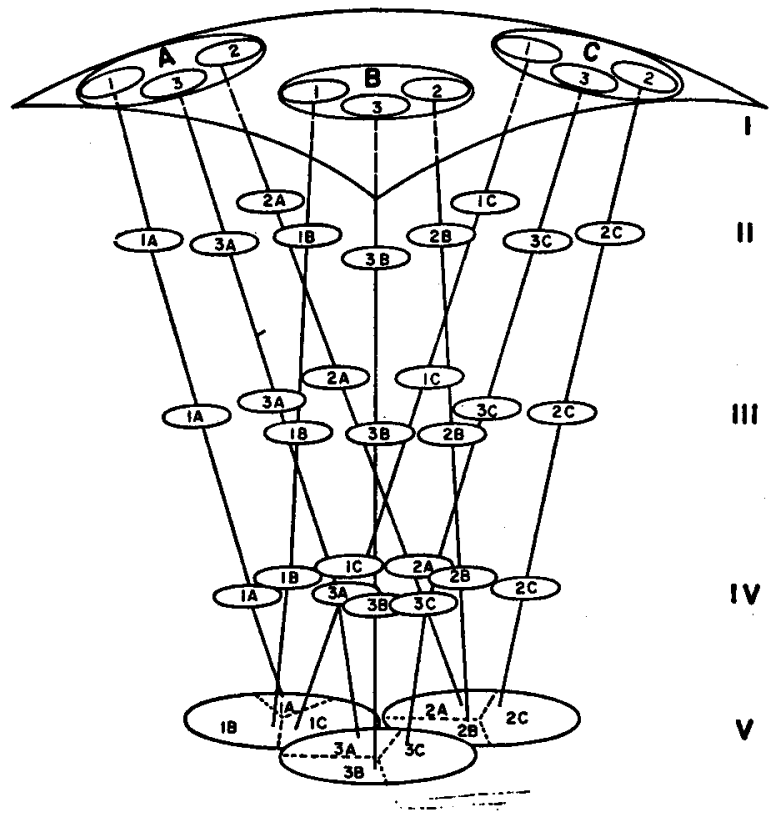

Figure.

Schematic vegetation model, based on vegetation in the $\mathrm{Ca}$ nadian Northern Great Plains

$\mathrm{A}, \mathrm{B}$ and $\mathrm{C}$ are habitat-types. 1,2 and 3 are climatic regions. $\mathrm{I}-\mathrm{V}$ are stages of successional development.

available data are hardly sufficient to allow for much detail at all stages of succession, they do substantiate the trend depicted in the model. For example, associations on habitat-type $A$, the Eriogonion or equivalent, would be succeeded by: -

- the Boutelouion gracilis in region 1 (cool temperature, semi-arid southern plains)

- the Danthonion intermediae in region 2 (cold temperature, sub-humid areas: the Cypress Hills, the foothills of the Rocky Mountains in Alberta, and the sub-boreal Parklands)

- an undescribed grassland type, which may be named "Stipion sparteae", in region 3 (cool temperature, sub-humid plains of southern Manitoba). 
Succession to optimal grassland is completed at stage III, and at this stage the three grasslands have several minor species in common but differ substantially in the dominants.

Stage IV represents the "shrub" stage. In region 2 Potentilla fruticosa is predominant; Rhus glabra is common in region 3. In all climatic regions Rosa acicularis and Symphoricarpos occidentalis are abundant; region 1 apparently has no true shrubby kensorts with the exception of Artemisia cana on sandy soils.

The climax is initiated in all regions with Populus tremuloides and Salix spp.; in addition, Pinus contorta or $P$. banksiana in region 2, and Quercus macrocarpa in region 3, may appear in the initial climax communities. Region 1 again has apparently no tree-kensorts, although further investigation of the genus Salix may show that some of its species can be used as kensorts for the semiarid southern plains.

The model shows that the theoretical climax is not a climatic climax in the sense of Clements (1928), but that climax communities within a climatic region are edaphically determined. The dominants in the climax communities, as in communities at all stages of succession, may be the same species on all habitat-types, but differentiation between communities remains possible through minor species indicative of different habitat-types. Some soils may not be capable of supporting the climax under any climate, while other soils may be prevented from development to suitable conditions through factors other than climate, e.g., grazing and/or burning.

Vegetation models show further that the concept of the plant association is not a contradiction of vegetational continuity. However, this continuity is exclusively successional. Continuity between habitat-types does not exist, only "overlap". This overlap may well be continuous in the sense that it is possible to form a continuous gradient from one habitat-type to another for any one factor, but apparently the interaction between the factors at any point on the gradient can cause a sudden steepening. Thus, the tension zones between climatic regions, the altitudinal zonation of vegetation, and the zonation on slopes or around bodies of water, cannot be explained easily in terms of single factors. The compounded effect of several simultaneously changing factors may well be the result of one single factor exceeding a threshold value, thus acting as a "trigger factor". BiLlings (1952) used this term for a limiting factor that is changed and then sets off a chain reaction in the ecosystem.

The "continuity" between overlapping associations is usually caused by species with wide ecological tolerance or dominants, and the same is true between overlapping alliances. The lacck of kensorts in sites of an "in-between" habitat-type seems to confirm the theory that the gradients between habitat-types are steeper than is apparent.

The plant association and the vegetational continuum have the same underlying cause: the ecological tolerance of plant species. But, whereas the "classifier" sees the species with narrow tolerance aggregate in describable associations on different habitattypes, the "continuist" sees the species with wide tolerance in several associations and on several habitat-types, thus uniting the associations into a continuum.

\section{Classification}

The ultimate purpose of classification is a practical one; to differentiate, describe and arrange units for reference. The ideal classification for scientific purposes should be universally valid, and afford workers in all parts of the world a means of comparing units in their regions with units described elsewhere. In plant taxonomy this 
ideal has been reached; the description and classification of taxa follow standard procedures, and the position and status of a new taxon, though debatable, are never in doubt.

In plant sociology the taxonomy of plant communities is far from this ideal. Even the most widely used system, that of Zürich-Montpellier, is not universally valid, and in its present form can never become universally valid. This is unfortunate because the methods and classification system used in the Z-M school are universally applicable. The validity of the system is limited only because of the criteria used in the delimitation of its units.

In contrast to plant taxonomy, where several criteria are used in the determination of a plant, the Z-M system uses a single criterion: floristics. Unless associations have species in common, they cannot be placed in the same alliance, order and class. The validity of the higher units, therefore, cannot extend over a wider geographic area than the distribution limits of class kensorts. A further disadvantage of the purely floristic basis of the system is that the higher units become ecologically more and more heterogeneous, because at higher levels only species with relatively wide ecological tolerance can be common to all lower units. This disadvantage has been partly overcome through the recognition of "regional" and "local" kensorts, which recognition is in effect a departure from the original concepts, and shows the desirability of maintaining a measure of ecological uniformity as well as the existence of different expressions of the "same" association in different regions. The result is, however, rather confusing to an outsider who finds that, for example, the Molinion coeruleae has different kengroups in different parts of Europe.

A more logical and more consistent system would place equal emphasis on all properties of the plant association. Essentially, the association is an ecological unit, representing a given phase in successional development, and its floristic composition is an expression of these properties by which one recognizes the association. Using these three criteria, only the indicators of the habitat-type of the association can serve as kensorts for the higher units. Consequently, all units are limited in geographic distribution by the climate. For example, the Eriogonion flavi of the Canadian prairies may be united into an order ("Eriogonetalia") with alliances elsewhere on the basis of common possession of, e.g. Eriogonum flavum, Haplopappus nuttallii and Hymenoxys richardsonii, which are high fidelity indicators of the habitat-type. Stipa comata, Bouteloua gracilis and Artemisia frigida cannot serve as order kensorts, because they are not indicators of the Eriogonion habitat-type. This limits the geographic distribution of the "Eriogonetalia" to the drier parts of the Great Plains of North America. However, if an order of similar ecology in a region with a similar climate and representing the same successional phase exists elsewhere, this order may be united in one class with the Eriogonetalia. In many instances the life-form spectrum of an association is distinctive, and this might well be used as an additional criterion.

The feasibility of a universally valid classification has been demonstrated by CHAPMAN (1959) with the vegetation of salt marshes. However, because his alliances and orders are intended to be universally valid (or at least in a large part of the world), these units cannot be distinguished by kengroups. In some instances this is not a great disadvantage: it would be very simple to place the Salicornietum rubrae of the Canadian prairies in the alliance:- Salicornion CHAP., and order:- Coeno-Salicornietalia CHAP. When more advanced comunities as the haline meadows are involved, matters become less simple. Here the lack of floristic expression of ecological uniformity in 
Chapman's system is a decided disadvantage, in the same manner as the lack of ecological uniformity is a disadvantage in the present system of Zürich-Montpellier.

One of the main advantages of a universally valid classification is the comparability of its units. This comparison may be taxonomical or practical. In the practical sense units may be compared, to plot the distribution of species, to determine the ecological tolerance of species, or to compare management practices in pasture or forest research. Research on plant communities in one part of the world may well be applicable in the counterparts of these communities elsewhere, and introduction of exotic species might be done on a rational, rather than trial and error basis.

The work of KRUIJNE and DE VRIES (1963) in the Netherlands may serve as an illustration of this point. These workers have determined the synecological range of tolerance and indicative value of many grassland species for several environmental factors, on the basis of the abundance of these species in pastures and haylands. The pastures of good to excellent quality in their studies are classified as the association Lolieto-Cynosuretum.

If grassland associations with an ecology similar to that of the Lolieto-Cynosuretum were placed in a single class in which each order and alliance is limited in its distribution by climatic conditions, direct comparison of associations in this class would be possible. Comparisons can include yield, desirability (palatability, grazing resistance) and hardiness of species, and possibilities for improvement. The choice of exotics to be introduced can be narrowed down considerably, and experiments with exotics can be aimed at verification of expected results. Seed mixtures can be composed of the best adapted of the desirable species, and artificial communities can be created and maintained. Thus, in the sub-boreal Parklands of the northern Great Plains, where natural grasslands are of inferior quality and low yield, seeding of cultivated pastures is necessary. Some species of the Lolieto-Cynosuretum do well in the region, e.g. Phleum pratense, Poa pratensis, Festuca rubra var. genuina, and Agrostis stolonifera. Available data on established pastures are scarce, but the few do indicate that the behaviour of these species conforms to that expected from the data of KRUIJNE and DE VRIEs (1963). Hence, these data can serve as a basis for experimentation and recommendations. However, a wider choice of species is desirable in view of climatic variations in the region, and at present a rational choice is not possible.

\section{Conclusions}

From the foregoing, Gleason's question may be answered with a definition of the plant association:

A plant association is an aggregate of plant species forming an ecological unit with a definite successional status and of uniform physiognomy, recognizable by its floristic composition.

This definition of the association justifies the methods of selecting stands and description of associations as practiced by the Zürich-Montpellier school: only "typical" stands possess the salient features of the association, and all modifications must be regarded as sub-associations or variants. The definition also affords the possibility of using several criteria in the differentiation and classification of vegetation units, and of making this classification universally valid and thereby more useful.

\section{REFERENCES}

Billings, W. D. 1952 The environmental complex in relation to plant growth and distribution. Quart. Rev. Biol. 27, 251--265. 
Braun-Blanquet, J. Chapman, V. J.

Clements, F. E.

CuRTIS, J. T.

Damman, A. W. H., and D. M. DE VRIES

Gleason, H. A.

GooD, R.

Kruijne, A. A., and D. M. DE VRIES

\section{LOOMAN, J.}

VRIES, D. M. DE, J. P. Baretta and G. HAMMING

WEAVER, J. E., and W. E. BRUNER

WHITTAKER, R. H.
1951 Pflanzensoziologie. 2nd ed., Wien, 631 pp.

1959 Salt marshes and ecological terminology. Vegetatio. 8, 215234.

1905 Research methods in ecology. Univ. Publishing Co. Lincoln (Nebr.) 334 pp.

1959 The vegetation of Wisconsin. Univ. Wisconsin Press, Madison (Wis.) $657 \mathrm{pp}$.

1928 Plant succession and indicators. H. W. Wilson Co., New York, $453 \mathrm{pp}$.

1954 Testing of grassland associations by combinations of species. Biol. Jaarb. 21, 35--46.

1939 The individualistic concept of the plant association. Am. Midl. Naturalist. 21, 92-110.

1953 The geography of flowering plants. Longmans, Green \& Co., London, $452 \mathrm{pp}$.

1963 Data concerning important herbage plants. Inst. Biol. Scheik. Onderz. Landb.gew., Wageningen, Meded. No. 225 (stencilled report).

1962 Licken and bryophyte communities in prairie grasslands. Ph. D. thesis. Univ. Wisconsin.

1963 Preliminary classification of grasslands in Saskatchewan. Ecology. 44, 15-29.

1964 The distribution of some lichen communities in the Prairie Provinces and adjacent parts of the Great Plains. Bryologist. 67, 209-224.

1954 Constellation of frequent herbage plants based on their correlation in occurrence. Vegetatio. 5/6, 105-111.

1954 Nature and place of transition from the true prairie to mixed prairie. Ecology. 35, 117-126.

1962 Classification of natural communities. Bot. Rev. 28, 1-239. 